\title{
Development of Cd (II) Ion Probe Based on Novel Polyaniline-Multiwalled Carbon Nanotube-3-aminopropyltriethoxylsilane Composite
}

\author{
Raja S. Alruwais 1,2 , Waheed A. Adeosun 1,3, Amjad E. Alsafrani 1,4 ${ }^{\text {, Hadi M. Marwani }}{ }^{1,3, *}$, \\ Abdullah M. Asiri ${ }^{1,3}\left(\mathbb{D}\right.$, Imran Khan ${ }^{5}$, Mohammad Jawaid ${ }^{6, *} \mathbb{D}$ and Anish Khan 1,3,*
}

1 Chemistry Department, Faculty of Science, King Abdulaziz University, Jeddah 21589, Saudi Arabia; rajaotb@gmail.com (R.S.A.); dsnwaheed1@gmail.com (W.A.A.); Amjad.chem@hotmail.com (A.E.A.); aasiri2@kau.edu.sa (A.M.A.)

2 Department of Chemistry, Faculty of Science and Humanities, Shaqra University, Dawadmi 11911, Saudi Arabia

3 Center of Excellence for Advanced Materials Research, King Abdulaziz University, Jeddah 21589, Saudi Arabia

4 Department of Chemistry, College of Science, University of Jeddah, Jeddah 21589, Saudi Arabia

5 Applied Sciences and Humanities Section, University Polytechnic, Faculty of Engineering and Technology, Aligarh Muslim University, Aligarh 202002, India; imrannano@gmail.com

check for updates

Citation: Alruwais, R.S.; Adeosun, W.A.; Alsafrani, A.E.; Marwani, H.M.; Asiri, A.M.; Khan, I.; Jawaid, M.; Khan, A. Development of Cd (II) Ion Probe Based on Novel PolyanilineMultiwalled Carbon Nanotube-3aminopropyltriethoxylsilane Composite. Membranes 2021, 11, 853. https://doi.org/10.3390/ membranes 11110853

Academic Editors:

Natalia Pismenskaya and Hsueh-Chia Chang

Received: 13 September 2021

Accepted: 28 October 2021

Published: 4 November 2021

Publisher's Note: MDPI stays neutral with regard to jurisdictional claims in published maps and institutional affiliations.

Copyright: (c) 2021 by the authors. Licensee MDPI, Basel, Switzerland. This article is an open access article distributed under the terms and conditions of the Creative Commons Attribution (CC BY) license (https:/ / creativecommons.org/licenses/by/ $4.0 /)$.
6 Laboratory of Biocomposite Technology, Institute of Tropical Forestry and Forest Products (INTROP), University Putra Malaysia, UPM, Serdang 43400, Selangor, Malaysia

* Correspondence: hmarwani@kau.edu.sa (H.M.M.); jawiad@upm.edu.my (M.J.); akrkhan@kau.edu.sa (A.K.)

Abstract: Cadmium belongs to the group of potentially toxic metals that have high health and environmental significance. Due to its adverse effects on the environment, this study develops an effective electrochemical sensor for detecting a polyaniline-multiwalled carbon nanotube-3aminopropyltriethoxysilane (PANI-MWCNT-APTES) substrate cast on the GCE. The as-prepared PANI-MWCNT-APTES was prepared by a wet chemical method, and its formation was investigated using several techniques. As a result, the prepared material exhibited a limit of detection of $0.015 \mu \mathrm{M}$ for cadmium ions $\left(\mathrm{Cd}^{2+}\right)$ in the linear dynamic range of $0.05 \mu \mathrm{M}$ to $50 \mu \mathrm{M}$. Furthermore, the PANIMWCNT-APTES-modified GCE current response was stable, repeatable, reproducible, and short. In addition, PANI-MWCNT-APTES/GCE was harnessed for the first time for cadmium detection in real water samples, and the result was satisfactory. Therefore, the recorded results suggest that the newly designed PANI-MWCNT-APTES is a promising material for detecting $\mathrm{Cd}$ in the near future for human health and environmental protection.

Keywords: linear sweep voltammetry; heavy metal detection; environmental pollution; cadmium ion detection; electrochemical sensors; potential toxic metals

\section{Introduction}

The world at large has consistently witnessed ever-increasing environmental pollution over the years, especially in the aquatic environment (water bodies), due to growing industrial establishment and operations. The effluents arising from industrial operations contain many toxic chemicals and potentially toxic metals (PTMs), which include metal ions such as cadmium. Cd (II) is highly generated from industrial processes such as textile operation, tanning, aluminum extrusion, agricultural processes, etc. [1-3]. The resultant effluents from the aforementioned industrial processes enter oceans and rivers and even percolate into underground aquifers [4]. Through this, $\mathrm{Cd}^{2+}$ interferes with aquatic lives and even affects humans through the oral route $[5,6]$. The toxicity of $\mathrm{Cd}^{2+}$ lies in its ability to bioaccumulate on living organisms, from trace concentrations to much higher concentrations [5]. At a certain concentration, $\mathrm{Cd}^{2+}$ becomes highly toxic to humans and another living organism 
in the biota. The permissible limit of $\mathrm{Cd}^{2+}$ in potable water and surface water indicated by the World Health Organization are $3 \mathrm{ng} / \mathrm{mL}$ and $5 \mathrm{ng} / \mathrm{mL}$, respectively [7,8]. A higher concentration of $\mathrm{Cd}^{2+}$ has been implicated in several health problems including kidney dysfunction, cancer, a blood disorder, and bone pain [9-11]. Due to its health significance and threat, there is a need for research on developing a sensitive and effective method of $\mathrm{Cd}^{2+}$ detection and monitoring in the environment, especially in drinking water and oceans. In the past and even till now, several efforts have been expended on developing methods of $\mathrm{Cd}^{2+}$ detection. These methods include atomic absorption spectrophotometry [12], inductively coupled plasma spectrophotometry [13], UV spectrophotometry [14], etc. These methods are sensitive and suitable for $\mathrm{Cd}^{2+}$ detection; however, they suffer setbacks in their high cost of analysis, cumbersomeness in sample preparation and equipment operation, high time consumption, unsuitability for in situ analysis, etc. Therefore, to address this problem, a fast, reliable, and sensitive method is required. An electrochemical method fits this, as it is speedy, reliable, suitable for in situ analysis, and cheap $[15,16]$. Therefore, the current study employs the electrochemical method for $\mathrm{Cd}^{2+}$ detection in water.

Previously, researchers have explored the detection of $\mathrm{Cd}^{2+}$ using the electrochemical method, but the methods suffer some setbacks such as result instability and high limits of detection. For instance, Hassanpoor et al., in their study, employed $\mathrm{MnO}$-reduced graphene oxide (rGO) nanocomposite $\mathrm{Cd}^{2+}$ sensing in an aqueous medium. The developed sensor displayed a high sensitivity with a relatively low limit of detection $(1.12 \mu \mathrm{g} / \mathrm{L})$. However, the current response of the developed sensor suffers instability in the presence of likely interferents, especially at high concentrations [17].

Wang et al. reported the detection of cadmium ion in wastewater using a thiacalix [4] arene (TC4A)-modified electrode. The electrochemical detection of $\mathrm{Cd}^{2+}$ was carried out using differential pulse anodic stripping voltammetry (DPASV). They reported a reduction in current responses in the linear dynamic range of $0.1-1 \mathrm{mg} / \mathrm{L}$ with a limit of detection of $4 \mu \mathrm{g} / \mathrm{L}$. The developed Cd ion sensor was reported to give good sensitivity and stability in water. However, the linear response of the sensor was deficient [18].

A lot of study is conducting on composite meterials for different applications because of high increase properties after making composite by involving individual initiators quality too [18-28]. Therefore, to improve the current response towards $\mathrm{Cd}^{2+}$ concentration, especially in terms of response stability, we explored a conducting polymer-based composite-coated electrode material. Specifically, the sensing material based on polyanilinemultiwalled carbon nanotube-3-aminopropyltriethoxysilane (PANI-MWCNT-APTES) composite was selected. The choice of this material was based on the excellent properties of the constituent of the composite. For instance, polyaniline is a conducting polymer with excellent properties such as high conductivity due to its delocalized pi-electron, high catalytic property, and high chemical stability [29,30]. In addition, the multiwalled carbon nanotube is a highly conductive and catalytic material, and it has equally good mechanical and chemical stability [31,32]. In addition, compositing MWCNT to PANI provides more active nucleation sites for PANI, excellent electron transfer, and good mechanical stability.

Therefore, compositing these materials is expected to result in a highly conductive, catalytic, and chemically stable material, which would have strong potential to act as electrocatalysts for electro-oxidation or for the reduction of heavy metal ions in an aqueous medium.

As far as we know, this study reports the synthesis of PANI-MWCNT-APTES composites for application as a $\mathrm{Cd}^{2+}$ electrochemical probe for the first-time.

\section{Experimentation}

\subsection{Reagents Used}

The reagents utilized for this research includes aniline monomers, multiwalled carbon nanotubes, potassium persulfates, hydrochloric acid, 3-aminopropyltriethoxysilane- $98 \%$, an acetate buffer, potassium ferricyanide, and deionized water obtained from Milli-Q plus 
system. All of the reagents were procured from Sigma Aldrich (St. Louis, MO, USA) USA and were used without any further purification.

\subsection{Instrumentation}

In this study, several techniques were used for material synthesis, characterization, and application. Among the instruments used are a Fourier Transform infrared spectrometer, FTIR (Perkin Elmer 2000, Waltham, MA, USA), a field emission scanning electron microscope, FESEM (JEOL JSAM 6300, Jeol, Tokyo, Japan), an X-ray diffraction spectrometer, XRD (X-Max Oxford Instruments, Abingdon, UK), an X-ray photoelectron spectrometer, XPS (Thermo Scientific Waltham, MA, USA), a thermogravimetric analyzer, TGA (Mettler Toledo, Greifensee, Switzerland), and an electrochemical work station (Autolab Potentiostat-PGSTAT302N-AUT85887) controlled by Nova 2.0 software. The electrochemical workstation comprises a working electrode (glassy carbon electrode-modified and bare), a reference electrode $(\mathrm{Ag} / \mathrm{AgCl}$-in $3 \mathrm{M} \mathrm{KCl})$, and a $0.5 \mathrm{~mm}$ wide platinum counter electrode. The electrical conductivity measurement was carried out using a fourprobe method on press pallets of the PANI@MWCNT-APTESP using the DMV-001 digital multimeter (SES instrumentation, PVT. LTD., Roorkee, India).

\subsection{Synthesis of PANI-MWCNT-APTES Composite}

Polyaniline was prepared by the conventional chemical oxidation method, where the oxidation of aniline monomer was achieved by potassium persulfate $\left(\mathrm{K}_{2} \mathrm{~S}_{2} \mathrm{O}_{8}\right)$. At first, a varying concentration of $0.1 \mathrm{M}$ aniline monomer was prepared in $1 \mathrm{M}$ hydrochloric acid to form aniline hydrochloride. Then, the oxidizing agent, $0.1 \mathrm{M} \mathrm{K}_{2} \mathrm{~S}_{2} \mathrm{O}_{3}$, was added gently to a varying volume of $0.1 \mathrm{M}$ aniline $(3,5$, and $7 \mathrm{~mL}$ dissolved in $100 \mathrm{~mL} 0.1 \mathrm{M}$ $\mathrm{K}_{2} \mathrm{~S}_{2} \mathrm{O}_{8}$ under vigorous stirring for $2 \mathrm{~h}$ at $0-4{ }^{\circ} \mathrm{C}$. The incorporation of MWCNTs into PANI was performed using a mechanical method. Initially, before crosslinking to PANI, MWCNT-APTES was synthesized. Specifically, $200 \mathrm{mg}$ of MWCNTs was dissolved in $50 \mathrm{~mL}$ ethanolic solution (65\% v/v) and was ultrasonicated for $1 \mathrm{~h}$. Subsequently, $2 \mathrm{~mL}$ of the APTES solution was added to the mixture. Finally, the mixture (APTES-MWCNTs) was added to the PANI matrix under vigorous stirring for $1 \mathrm{~h}$ to crosslink with PANI. The obtained PANI-MWCNT-APTES was then annealed at $75^{\circ} \mathrm{C}$ overnight. The as-prepared PANI-MWCNT-APTES composite was then obtained and used for the remaining studies.

\subsection{Fabrication of Electrodes for Sensing Application}

The synthesized PANI-MWCNT-APTES composite was applied as the substrate on the surface of GCE for sensing application. Before the sensing application, the unmodified glassy carbon electrode (b-GCE) was thoroughly cleaned under sonication. To remove the materials adhered onto the b-GCE surface, it was electrochemically cleaned by a cyclic voltammetric sweep in $0.25 \mathrm{M} \mathrm{H}_{2} \mathrm{SO}_{4}$. The clean b-GCE was then collected, and $1 \mathrm{mg}$ of the composite (PANI-MWCNT-APTES) was cast on it with the aid of $0.1 \mu \mathrm{L}$ of nafion. The coated PANI-MWCNT-APTES-modified GCE was then put in the oven to dry at $50{ }^{\circ} \mathrm{C}$ for $30 \mathrm{~min}$. The as-prepared PANI-MWCNT-APTES-GCE was then kept and used for further experiment.

\subsection{Electrochemical Studies}

The electrochemical studies of interest to this work include impedance spectroscopy, cyclic voltammetry, and linear sweep voltammetry. The frequency was set from $0.1 \mathrm{~Hz}$ to $100 \mathrm{kHz}$ at $0.005 \mathrm{~V}$ amplitude and $+0.2 \mathrm{~V}$ DC potential for the impedance spectroscopy. Cyclic voltammetry was used for electrochemical characterization using a potential window of $-1 \mathrm{~V}$ to $1.2 \mathrm{~V}$, a scan rate of $50 \mathrm{mV} / \mathrm{s}$, and a step potential of $0.008 \mathrm{~V}$. The LSV was performed using a potential window of $-1 \mathrm{~V}$ to $1 \mathrm{~V}$, a scan rate of $75 \mathrm{mV} / \mathrm{s}$, and a modulation time of $0.024 \mathrm{~s}$.

For the electrical conductivity measurement, $200 \mathrm{mg}$ of the as-prepared PANI-MWCNTAPTES was finely ground to make pellets made with the aid of a hydraulic pressure ma- 
chine operated at a pressure of $5 \mathrm{KN}$ imposed for $20 \mathrm{~min}$. A screw gauge determined the thickness of the pellets. The pellets made were subsequently used for electrical conductivity measurement at room temperature using the four-probe method.

\subsection{Real Sample Analysis}

In order to evaluate the efficacy of the developed probe for $\mathrm{Cd}^{2+}$ detection, real samples are collected and used for real-life $\mathrm{Cd}^{2+}$ determination. Seawater (obtained from Red Sea Jeddah, KSA) and underground water were used as real environmental samples. All of the samples were collected according to standard procedures and stored at $5{ }^{\circ} \mathrm{C}$. In order to remove the matrix effect, a 50 -fold dilution with acetate buffer was performed on the water samples. After that, a prepared standard solution of $\mathrm{Cd}^{2+}$ was spiked into the mixture, and the spiked concentration percentage recovery was determined.

\section{Results and Discussions}

\subsection{PANI-MWCNT-APTES Composite's Morphological Investigation}

The morphological property of the as-prepared PANI-MWCNT-APTES composite was studied through scanning electron microscopy (SEM). The obtained SEM images are given in Figure 1.
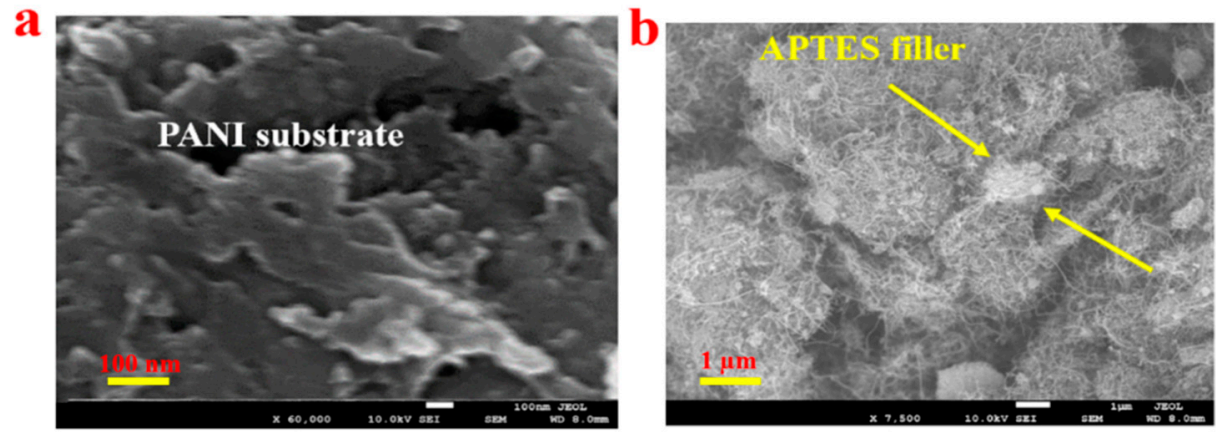

C
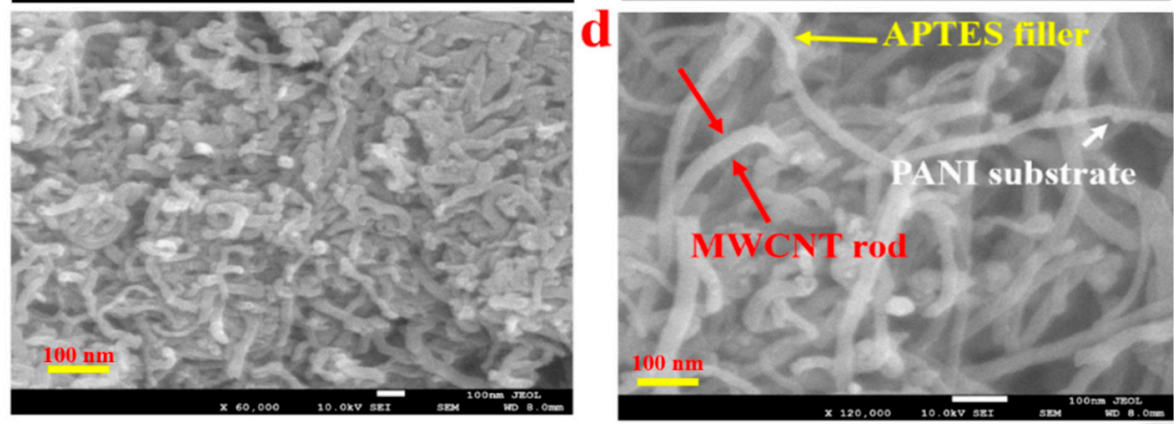

Figure 1. Scanning electron microscope images of (a) the PANI matrix, (b) the PANI-APTES composite, and (c) PANI-APTES-MWCNTs and (d) a magnified image of PANI-APTES-MWCNTs.

From the FESEM image observation, the PANI synthesized is a semi-amorphous porous layer. The incorporation of APTES into the PANI porous layers could be observed in Figure 1b. It could be suggested that APTES, in this case, acts as a filler to the PANI matrix. Further doping with a multiwalled carbon nanotube is evident in Figure $1 c, d$, where the nanorod of multiwalled carbon nanotube reinforced the PANI-APTES composite. Thus, the obtained images from the FESEM analysis are suggestive of a composite material.

\subsection{Elemental Study and Structural Investigation of PANI-MWCNT-APTES}

The elemental composition of the synthesized composite was investigated using energy-dispersive X-ray spectroscopy (XEDS). The obtained result is displayed in Figure 2a. The result indicates that the elements predominately present in the as-prepared samples were carbon, nitrogen, oxygen, and silicon, which is consistent with the actual constituent of PANI-MWCNT-APTES. 

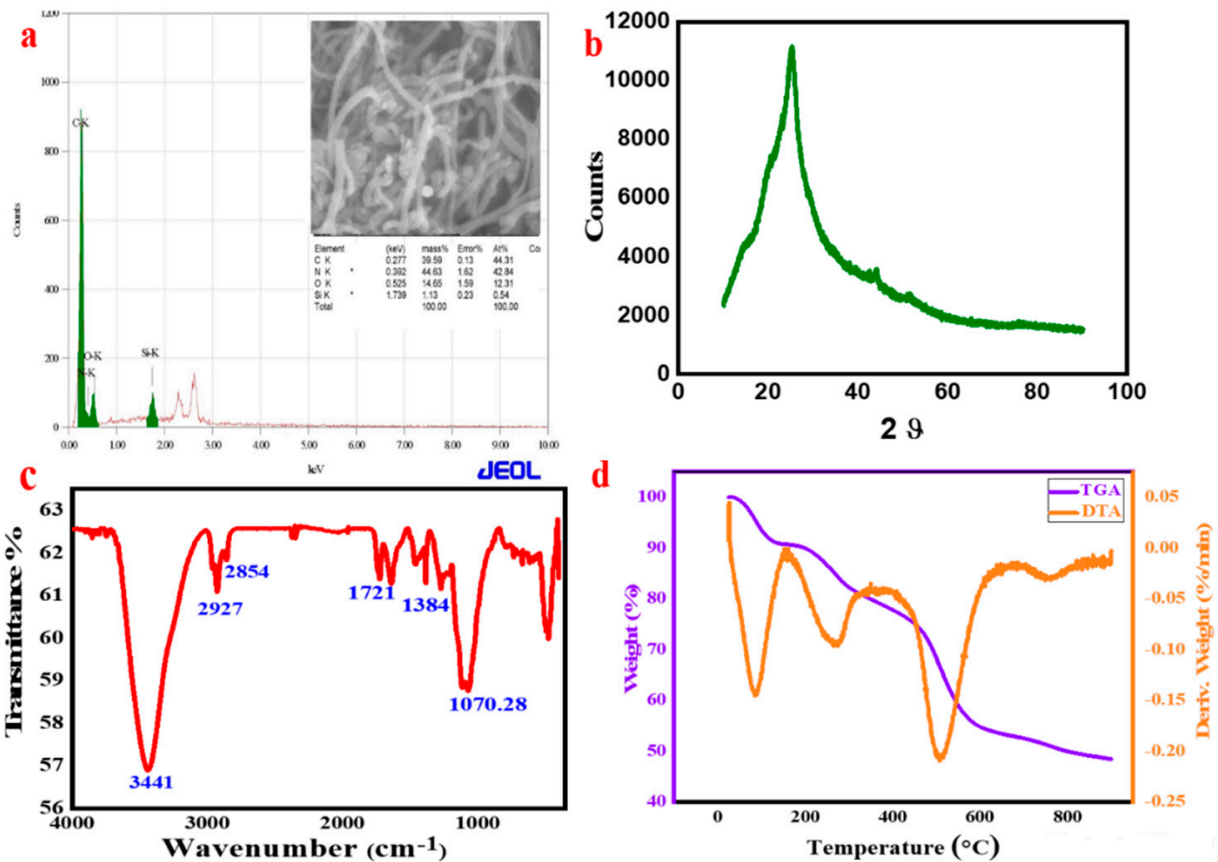

Figure 2. (a) XEDS spectrum of PANI-MWCNT-APTES, (b) XRD spectrum, (c) FTIR spectrum, and (d) TGA and DTG recorded for PANI-MWCNT-APTES.

The structural property of the synthesized PANI-MWCNT-APTES was assessed by $\mathrm{X}$-ray diffraction spectroscopy. The obtained XRD spectrum is given in Figure $2 b$. The diffraction peaks were recorded in the range of $10^{\circ}$ to $80^{\circ}$. The obtained prominent peaks at $14.5^{\circ}, 20.2^{\circ}$, and $25^{\circ}$ are peculiar to PANI, and the peaks are inconsistency with the (011), $(020)$, and $(200)$ planes $[33,34]$. The incorporation of MWCNT in the PANI matrix can be seen at a diffraction angle of $25.2^{\circ}$, inconsistent with the (002) phase [35]. The peak at $20^{\circ}$ is peculiar to PANI, and the angle diffraction peak at $24^{\circ}$ could be related to the silica group attached to the composite [36]. The obtained XRD spectrum revealed the non-crystallinity of the synthesized PANI-MWCNT-APTES.

\subsection{Functionalities Investigation Using Infrared Spectroscopy (FTIR)}

FTIR was conducted for the identification of the functionality in the as-prepared composite. The FTIR spectrum obtained was in the wavenumber range of $500 \mathrm{~cm}^{-1}$ to $4000 \mathrm{~cm}^{-1}$, as given in Figure 2c. The observed peaks at $2927 \mathrm{~cm}^{-1}$ and $2854 \mathrm{~cm}^{-1}$ are attributable to the methyl- $-\mathrm{CH}_{3}$ and $-\mathrm{CH}_{2}$ groups associated with PANI and MWCNT [37]. The peak at $1721 \mathrm{~cm}^{-1}$ is linked to the $\mathrm{C}-\mathrm{N}$ stretch in PANI. The N-H stretch in the PANI ring and APTES gives rise to the strong absorption peak observed at $3441 \mathrm{~cm}^{-1}[38,39]$. The $\mathrm{C}-\mathrm{N}$ vibration that could arise due to crosslinking between APTES/PANI and MWCNT might not be unconnected to the peak observed at $1650 \mathrm{~cm}^{-1}$. In addition, the $\mathrm{C}=\mathrm{C}$ in the conjugated PANI ring (benzenoid) could be linked to the peak at $1384 \mathrm{~cm}^{-1}$. The incorporation of APTES into PANI-MWCNT is confirmed by the peaks observed at $1100 \mathrm{~cm}^{-1}$ to $1070 \mathrm{~cm}^{-1}$, which is peculiar to the $\mathrm{Si}-\mathrm{O}-\mathrm{Si}$ and $\mathrm{Si}-\mathrm{O}-\mathrm{C}$ stretching vibration, respectively [40]. Therefore, the obtained FTIR results are suggestive of successful synthesis of PANI-MWCNT-APTES.

\subsection{Thermogravimetry Analysis (TGA)}

TGA is an important technique used to establish the stability of materials. The result of the TGA analysis is presented in Figure 2d. It could be observed that a weight loss of about $60 \%$ is recorded after 800 seconds. The material displayed good stability at an even higher temperature, which might be traced to the effect of MWCNT crosslinking the polymeric composite [41,42]. The differential thermal analysis (DTA) curve revealed three 
major endothermic reaction stages, namely at $103^{\circ}, 280^{\circ}$, and $520^{\circ} \mathrm{C}$. The obtained result suggests an endothermic reaction.

\subsection{Binding Energy}

The binding energy of the constituent elements in the as-prepared polymeric composite is presented in Figure 3. The binding energy is obtained through XPS. Similar to XEDS, the obtained results confirm the presence of carbon, nitrogen, oxygen, and silica. The absence of other peaks indicates the successful completion of the chapter. The full XPS spectrum is illustrated in Figure 3a. The deconvolution of peaks was carried out to reveal a different chemical state of the individual constituent's element present in the sample. The $\mathrm{C}$ 1s peak is deconvoluted into two peaks, namely at $284.7 \mathrm{eV}$ and $285.5 \mathrm{eV}$ (Figure 3c). The binding energy of $\mathrm{C} 1$ s gives a peak at PANI. The other peaks at 284.5, 285.8, 288.78, and $290.58 \mathrm{eV}$ could be linked to $\mathrm{C}-\mathrm{C}, \mathrm{C}-\mathrm{O}, \mathrm{C}-\mathrm{H}$ and $-\mathrm{COOH}$, and $\pi-\pi^{*}$ [43].
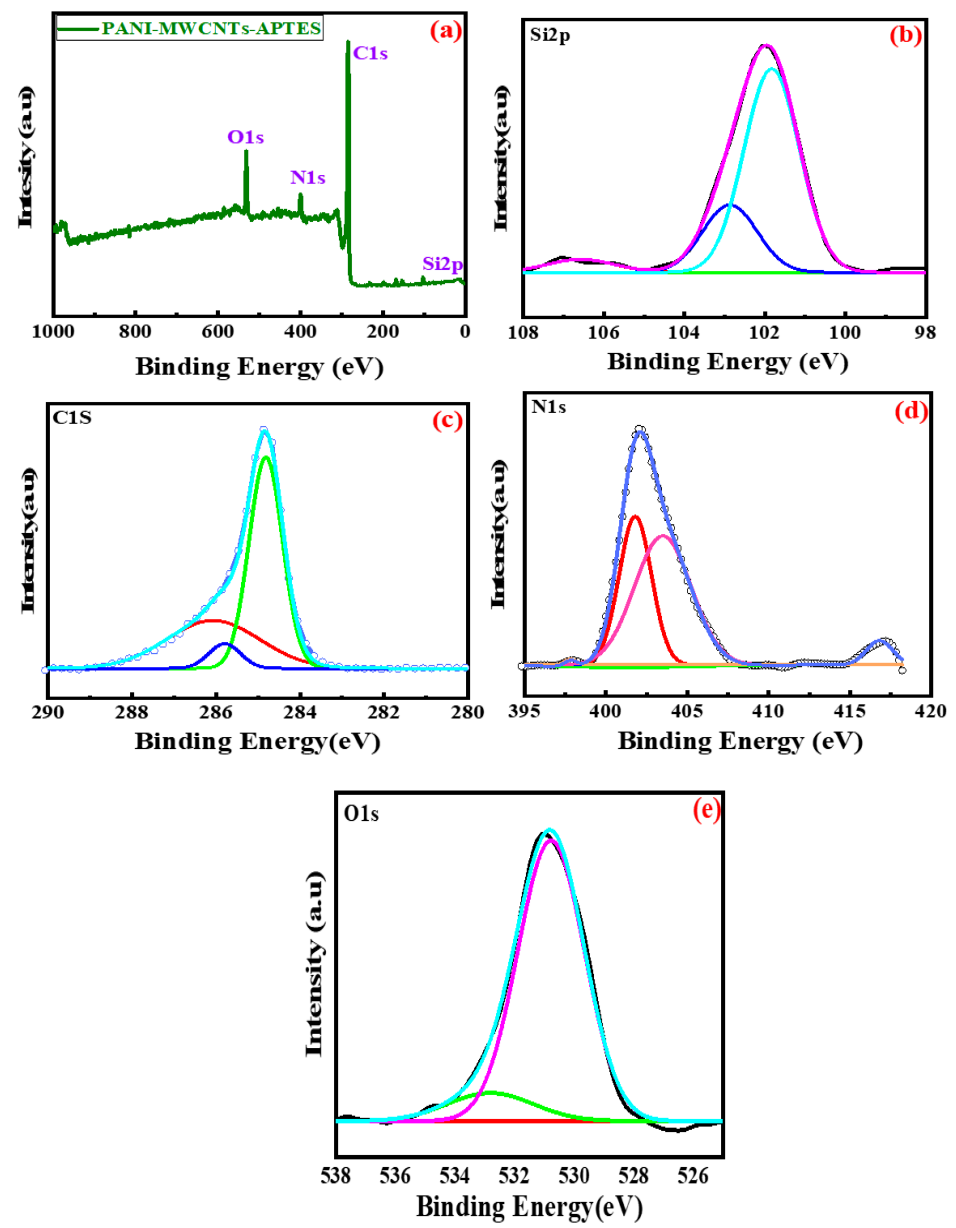

Figure 3. XPS spectrum of PANI-MWCNT-APTES: (a) Full spectrum. (b) Deconvoluted peak for Si. (c) Deconvoluted peak for C. (d) Deconvoluted peak for N. (e) Deconvoluted peak for O.

The peak at around $530 \mathrm{eV}$ is attributable to the oxygen peak. It was deconvoluted into two peaks, $531 \mathrm{eV}$ and $533.2 \mathrm{eV}$ belonging to $\mathrm{C}-\mathrm{O}$ bond of carboxylic acid in MWCNT and Si-O of triethoxylsilane constituent (Figure 3e). Finally, the peak observed at $100 \mathrm{eV}$ revealed peaks at 102 and $103 \mathrm{eV}$ attributable to Silica. (Si-O) of the triethoxylsilane (Figure 3b) [44]. Nitrogen also exhibits two peaks when deconvoluted, giving rise at $402 \mathrm{eV}$ and $416 \mathrm{eV}$ (Figure 3d). This peak, as indicated earlier, could be linked to N-H strong stretch of PANI and C-N of PANI/MWCNT [26]. 


\subsection{Electrical Conductivity of The PANI-MWCNT-APTES}

The PANI-MWCNT/APTES nanocomposite pellet's electrical resistivity was calculated by a sample conductivity test using the four-probe process. The electrical conductivity was determined using the following equations described in Supplementary S1 [45].

At room temperatures, the electrical conductivity variation $(\sigma)$ of the as-prepared PANI-MWCNT/APTES nanocomposite (3\%, 5\%, and 7\% PANI concentration constituents) is presented in Figure 4a and Supplementary Table S1. The critical concentration of PANI in PANI@MWCNT/APTES for the highest conductivity was found (7\%), as shown in (Figure 4a). Therefore, the composite using higher PANI contents has lower electrical resistivity at $1.63 \Omega \mathrm{cm}$ and higher conductivity, calculated by the formula described in Supplementary S1.
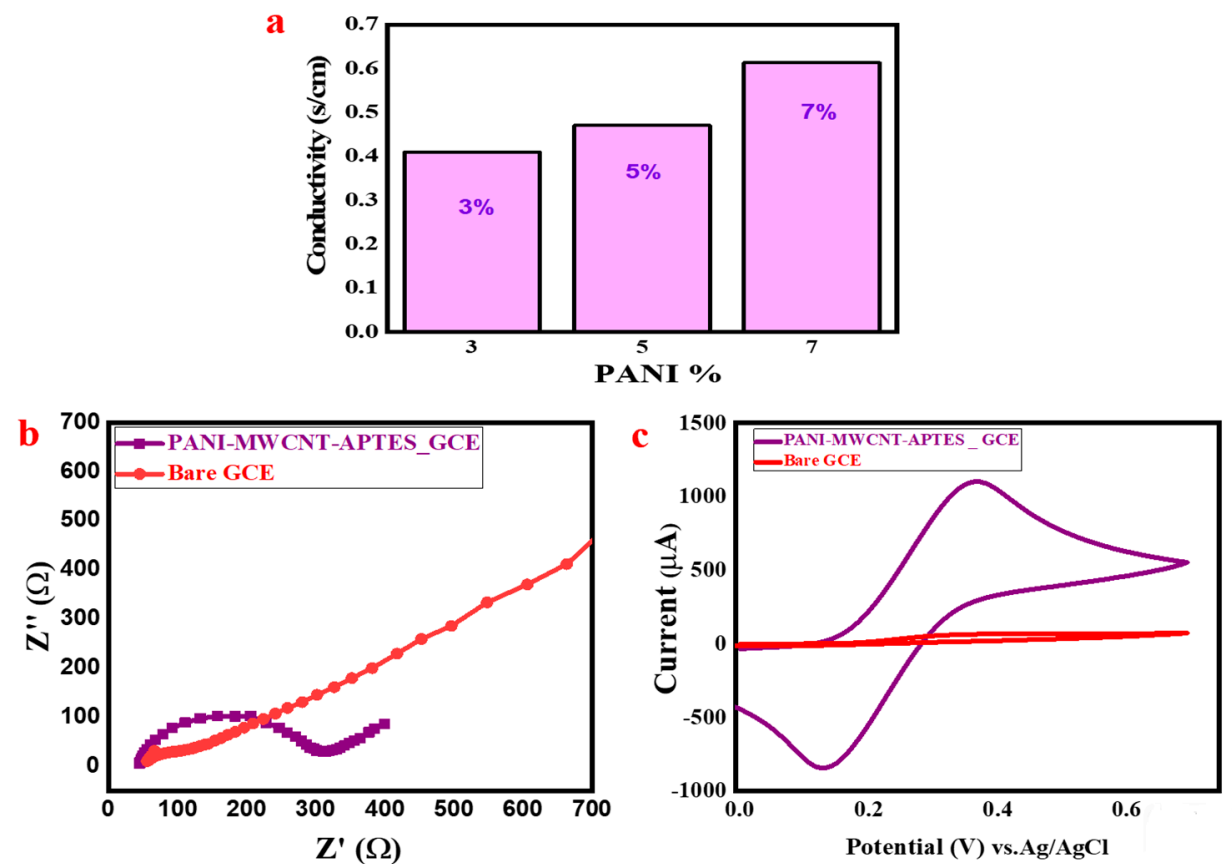

Figure 4. (a) A chart showing the electrical conductivity of the as-prepared PANI-MWCNT-APTES. (b) The obtained Nyquist plot for PANI-MWCNT-APTES. (c) The obtained CV in a ferricyanide couple $\left(1 \mathrm{mM} \mathrm{Fe}(\mathrm{CN})_{6}^{3-/ 4-}\right.$ prepared in $\left.0.1 \mathrm{M} \mathrm{KCl}\right)$.

\subsection{Electrochemical Behavior Investigation}

The EIS and CV behavior in potassium ferricyanide couples was studied, as was the electrochemical behavior of the as-prepared material (PANI-MWCNT-APTES). The result of the EIS study is given in Figure $4 \mathrm{~b}$. The EIS was obtained from the plot of imaginary impedance and against the real impedance. The plot of these two is expressed as the Nyquist plot. The semi-circle of the Nyquist plot refers to the charge transfer resistance (Rct), a function of the conductivity/resistivity. The smaller the Rct, the better the mobility of the charge/ion in the electrolyte [44,46]. For this study, the obtained Rct for PANIMWCNT-APTES is $131 \Omega$, while that of the bare electrode was $271 \Omega$ (Supplementary Figures S1 and S2). Therefore, the value obtained for PANI-MWCNT-APTES-modified GCE is smaller than that for the bare one and therefore has less resistance.

In addition, the cyclic voltametric response in the $1 \mathrm{mM} \mathrm{Fe}(\mathrm{CN})_{6}{ }^{3-/ 4-}$ solution is given in Figure 4c. The PANI-MWCNT-APTES-GCE displayed a higher oxidation $(1 \mathrm{~mA})$ with a smaller peak-to-peak potential $(395 \mathrm{mV})$. These phenomena indicate a faster electrochemical reaction on the PANI-MWCNT-APTES surface compared with bare GCE. 


\subsection{Electrochemical Sensing of $\mathrm{Cd}^{2+}$}

The response of the fabricated material (PANI-MWCNT-APTES) coated on glassy carbon electrode towards a $\mathrm{Cd}^{2+}$ ion was examined using electrochemical techniques: cyclic voltammetry and linear sweep voltammetry.

\subsubsection{Control Study}

To start with, a controlled study was conducted to confirm that the recorded current response was due to the effect of PANI-MWCNT-APTES. The obtained result for the control experiment is presented in Figure 5a. It could be observed that, in the absence of PANI-MWCNT-APTES on the GCE, this was a tiny reduction in the current at a higher voltage, at $-0.64 \mathrm{~V}$. However, PANI-MWCNT-APTES-modified GCE displayed a sharp higher reduction peak at the reduced potential $(-0.7 \mathrm{~V})$. Moreover, the individual effect of the constituent PANI-MWCNT-APTES composite was investigated. As a result, PANIonly-modified GCE gave less reduction in the current at $-0.7 \mathrm{~V}$ than PANI-MWNT-APTES. This indicates that the composition of PANI with MWCNT-APTES drastically improved the catalytic performance of PANI, thereby leading to its effectiveness in catalyzing the reduction of $\mathrm{Cd}^{2+}$ to zerovalent $\mathrm{Cd}$.

\subsubsection{PH Optimization}

To start with, the effect of $\mathrm{pH}$ on the reduction in the current response exhibited by PANI-MWCNT-APTES towards $\mathrm{Cd}^{2+}$ ions was studied. The obtained result is presented in Figure $5 \mathrm{~b}$. The optimal result (highest reduction in the current) was obtained at $\mathrm{pH} 5.6$ (HAc-NaoAc buffer), while the smallest current response was observed in the acidic phosphate buffer ( $\mathrm{pH}$ 5.8). This study was conducted in an acidic medium because, in the alkaline medium, cadmium was precipitated with a clear visible white precipitate. This resulted in low or no reduction in the current (Figure not shown). The reason for the low reduction in the current could be associated with possible electrode surface fouling. Moreover, the solubility of metal ions decreases with an increase in $\mathrm{pH}$ medium, which could be why, at the essential medium, the concentration of $\mathrm{Cd}^{2+}$ reduced [47]. Therefore, the optimal $\mathrm{pH}$ was 5.6, and this was maintained for the remaining experiment.

In addition, the scan rate effect on the reduction in current response of PANI-MWCNTAPTES was also studied. The purpose of the scan rate study was to determine whether the electrochemical reduction of $\mathrm{Cd}^{2+}$ ion on the GCE substrate is a diffusion control or adsorption-controlled. Usually, a linear dependence of the current on the scan rate plus having the slope of the current against the scan rate in the range of $0-0.5$ are indications of diffusion-controlled reactions. For this study, the current response increased with an increase in the scan rate with a correlation of 0.98 Equation (1). The correlation value (0.98) might suggest a non-linear relationship, and this would result in an adsorption-controlled reaction.

$$
\text { ip }(\mu \mathrm{A})=63.275 \times v^{1 / 2}+6.9337\left(\mathrm{R}^{2}=0.98\right)
$$

As given in [48,49], the slope of the logarithm of reduction in the current plot against the logarithm of the scan rate that fell below 0.5 indicates a diffusion-controlled reaction. In contrast, the one close to 1 indicates an adsorption-controlled process. Thus, for this study, the slope obtained for the plot of the current reduction logarithm against the scan rate logarithm is 0.765 (Equation (2)).

$$
\log \operatorname{ipc}(\mathrm{A})=0.765 \times \log \mathrm{v}(\mathrm{V} / \mathrm{s})-4.13 .
$$

This indicates that the reduction process of $\mathrm{Cd}^{2+}$ ion on the PANI-MWCNT-APTESmodified GCE was proceeded by the adsorption-controlled process. 

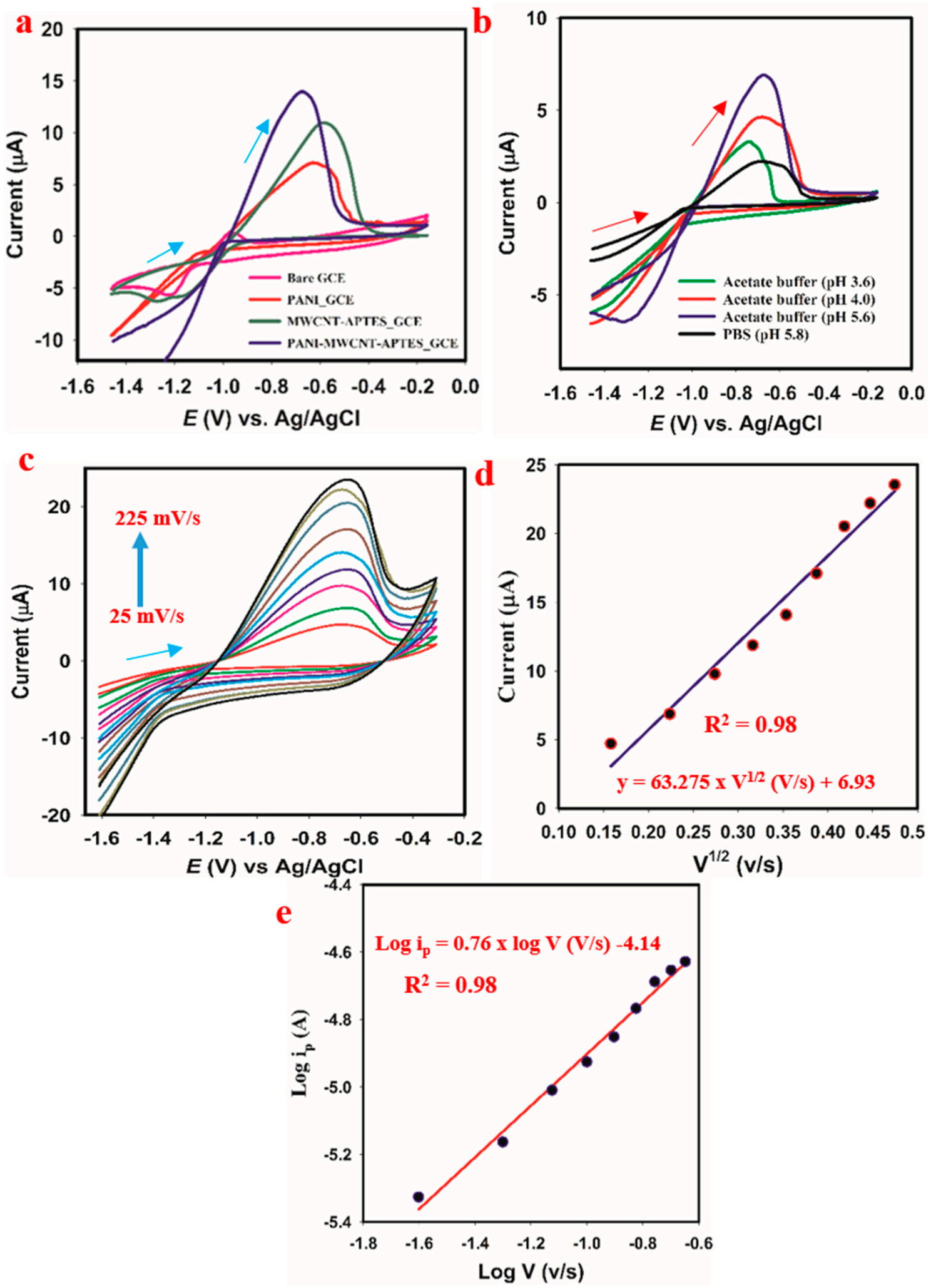

Figure 5. Electrochemical sensing responses: (a) effect of $\mathrm{pH}$ medium on the reduction in the current response exhibited by PANI-MWCNT-APTES in $15 \mu \mathrm{M} \mathrm{CdSO}_{4}$. (b) Control study in $50 \mu \mathrm{M} \mathrm{CdSO}_{4}$. (c) The obtained CV upon variation of the scan rate in $30 \mu \mathrm{M} \mathrm{CdSO}_{4}$ (d) Linear plot of the scan rate variation against current. (e) Linear plot of the logarithm for a reduction in current versus the logarithm of the scan rate. 


\subsubsection{Effect of Increase in $\mathrm{Cd}^{2+}$ Concentration on the Current Response}

The effect of varying concentrations of $\mathrm{Cd}^{2+}$ ion was investigated using linear sweep voltammetry. Linear sweep voltammetry was employed for this study because it is very accurate and is best suited for irreversible reactions [50,51]. This technique is based on the mechanism of measurement of the current given when the potential between the working electrode and the reference electrode varied linearly with time. The mechanism of $\mathrm{Cd}^{2+}$ detection is through the reduction and deposition of zerovalent $\mathrm{Cd}$ on the surface PANI-MWCNT-APTES-modified GCE. This type of reaction is irreversible, as presented in Equation (3).

The obtained linear sweep voltammogram is given in Figure 6a. The result indicates a linear increase in the current reduction response with an increase in the $\mathrm{Cd}^{2+}$ ion concentration. This reduction in current indicates the reduction of $\mathrm{Cd}^{2+}$ to zerovalent $\mathrm{Cd}$, as suggested in Equation (3).

$$
C d^{2+}+2 e^{-} \rightarrow C d
$$

The slope of the calibration showed a linear relationship between the two parameters (concentration and current) with a correlation of $0.98 \%$.

\subsubsection{Evaluation of Sensor's Performance}

The developed method of $\mathrm{Cd}^{2+}$ ion detection based on linear sweep voltammetry was assessed on some analytical performance parameters such as detection limit (LOD), the limit of quantification (LOQ), sensor's sensitivity, linear dynamic range (LDR), full dynamic range (FDR), and response time.

The LOD was calculated using the following formula (Supplementary S2):

$L O D=[3 \times S d$ of the blank]/[slope of the calibration plot $]$

The obtained value was $0.0155 \mu \mathrm{M}$, as shown in Supplementary S2.

The LOQ was calculated using the following formula:

$L O Q=10 \times[$ standard deviation of the blank]/[slope of the calibration plot]

The obtained value was $0.0517 \mu \mathrm{M}$, as shown in Supplementary S2.

The LDR indicates the range at which there is linear dependence of the current on the concentration. This ranged from $0.05 \mu \mathrm{M}$ to $50 \mu \mathrm{M}$. However, the FDR indicates the full concentration range at which current response to the change in concentration was noticed. For this study, this ranged from 0 to $50 \mu \mathrm{M}$.

The sensitivity of PANI-MWNT-APTES-modified GCE to $\mathrm{Cd}^{2+}$ ions was obtained using the following formula:

Sensitivity $=$ slope of the calibration/surface area of the GCE

The obtained value was $4.237 \mu \mathrm{A} \mu \mathrm{M}^{-1} \mathrm{~cm}^{-2}$, as shown by Supplementary S2.

Response time is a significant parameter in sensing applications because it indicates the time frame for the electrochemical process. Usually, a sensor with a fast response time is desirable for in situ analysis [52]. For this study, the response time recorded was $9 \mathrm{~s}$ (Figure 6f).

The stability of the current response of PANI-MWCNT-APTES was investigated by repetitive measurement techniques (repeatability and reproducibility). While repeatability indicates the accuracy of a method, reproducibility shows the precision of the sensor's performance. For this study, ten consecutive measurements at the same experimental condition were conducted, and the obtained result is given in Figure 6c. The RSD of the mean value was $0.7 \%$. For reproducibility, four different electrodes were modified with PANI-MWCNT-APTES, and their current response taken at different times was taken (Figure $6 \mathrm{~d}$ ). The RSD of the current responses of the four electrodes was $2.8 \%$. 

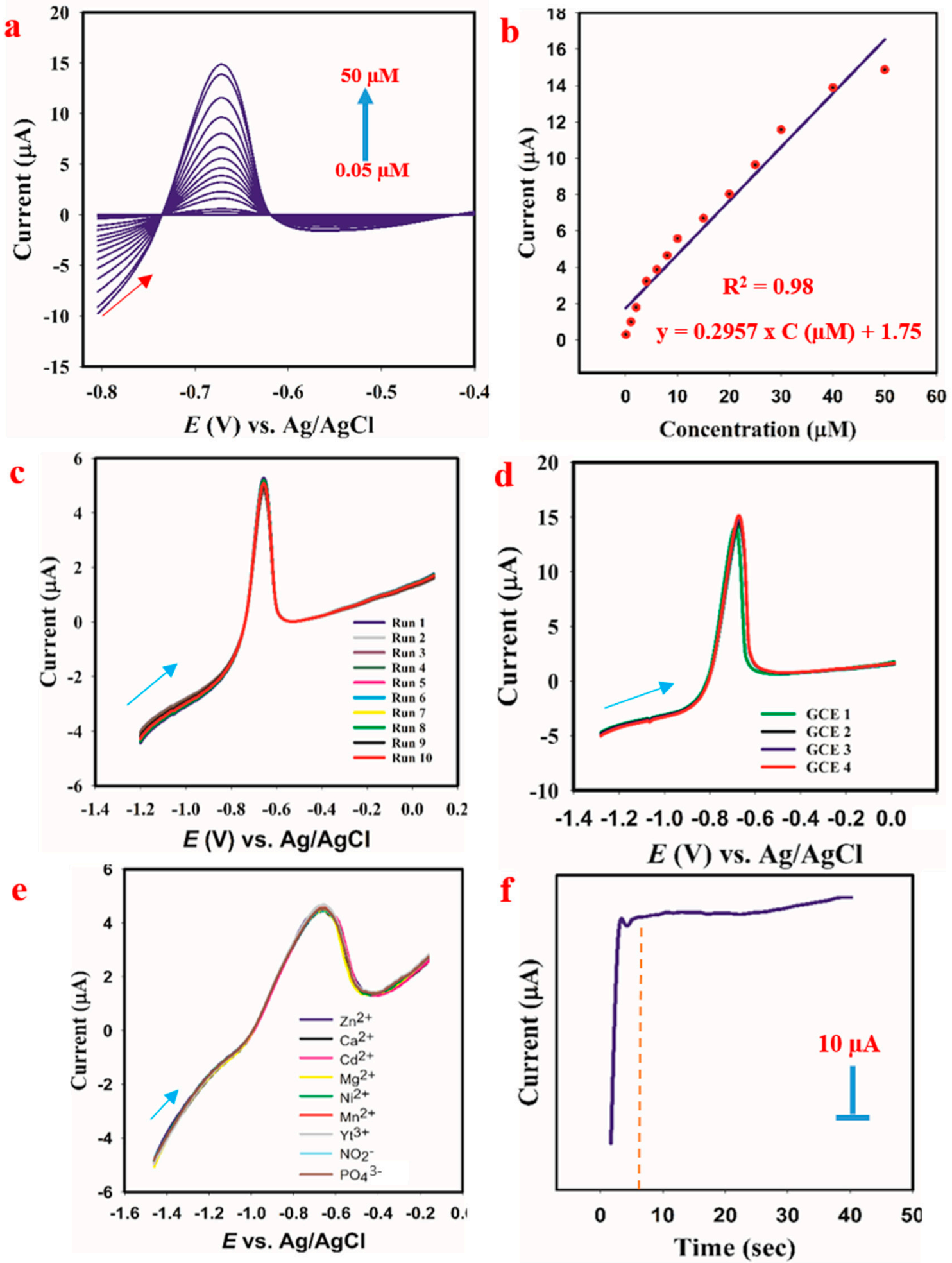

Figure 6. (a) Effect of varying the $\mathrm{Cd}^{2+}$ ion concentration. (b) Linear plot of current response against $\mathrm{Cd}^{2+}$ concentration. (c) Repeatability test. (d) Reproducibility test. (e) The effect of interferents on current response. (f) The recorded response time.

\subsubsection{Interferents' Effect on the Current Response}

Usually, metal ions with similar charges tend to interfere with the redox reaction of each other. For instance, $\mathrm{Cd}^{2+}$ has two positive charges $(2+)$ and is prone to interferents from metal ions with similar charges. Therefore, likely interfering ions mostly considered for this study are $\mathrm{Mg}^{2+}, \mathrm{Mn}^{2+}, \mathrm{Ni}^{2+}, \mathrm{Ca}^{2+}, \mathrm{Zn}^{2+}, \mathrm{Yt}^{3+}, \mathrm{NO}_{2}{ }^{-}$, and $\mathrm{PO}_{4}{ }^{3-}$. The obtained result 
is given in Figure 6e. It could be observed that, upon spiking of these likely interferents, the reduction current of $\mathrm{Cd}^{2+}$ ions was reduced slightly. However, the relative standard deviation (RSD) of the mean value of $\mathrm{Cd}^{2+}$ ions is less than $5 \%$. Therefore, the response of PANI-MWCNT-APTES is stable in the matrix containing likely interferents.

\subsubsection{Real Sample Analysis}

As indicated in Section 2.6, the real samples used for this study are underground water and seawater. The percentage recovery method used for this study is described in the Supporting Electronic Information (Supplementary S3). The obtained result is given in Table 1.

Table 1. Results for determining Cd (II) in real water samples.

\begin{tabular}{cccccc}
\hline Sample & Added $(\mu \mathrm{M})$ & Found $(\mu \mathrm{M})$ & Bias & Recovery $(\%)$ & RSD (\%) \\
\hline \multirow{3}{*}{ Underground water } & 0 & 0 & - & - & - \\
\cline { 2 - 6 } & 10 & $10.58 \pm 0.14$ & 0.58 & 105.8 & 1.3 \\
\cline { 2 - 6 } Seawater & 50 & $51.84 \pm 0.13$ & 1.84 & 103.7 & 0.25 \\
\cline { 2 - 6 } & 0 & 0 & - & - & - \\
\hline & 10 & $10.36 \pm 0.08$ & 0.36 & 103.6 & 0.77 \\
\hline
\end{tabular}

The percentage recovery for the spiked $\mathrm{Cd}^{2+}$ ranged from $103.6 \%$ to $129.9 \%$. Thus, the obtained result is satisfactory and suitable for use in real water samples.

\subsubsection{Comparison with Literature}

Table 2 presents previous studies on the detection of $\mathrm{Cd}^{2+}$ using different methods. Compared with the earlier reported method, the current study compares very well with the literature and even outperformed many. Significant progress on $\mathrm{Cd}^{2+}$ ion assays is the stability of PANI-MWCNT-APTES-modified GCE towards the $\mathrm{Cd}^{2+}$ reduction process. The typical setback in metal ion detection is electrode fouling, which makes the substrate (coated material) on the GCE have an unstable current response. However, it is suggested that crosslinking of MWCNT to the PANI-APTES matrix could have contributed to the anti-fouling nature of the PANI-MWCNT-APTES substrate.

Table 2. Comparison of the developed method in this study with the selected existing methods.

\begin{tabular}{|c|c|c|c|c|}
\hline Electrode/Substrate & Methode & Linear Range (LR) $\mu \mathrm{M}$ & $\begin{array}{l}\text { Limit of Detection } \\
\text { (LOD) } \mu \mathrm{M}\end{array}$ & Ref. \\
\hline Catechol-dithiol & DPV & $15-35$ & 4.5 & [53] \\
\hline $\mathrm{Ag}_{2} \mathrm{~S}$ quantum dots & Fluorescence & $1.0-40$ & 0.55 & [54] \\
\hline CdSe quantum dots & Flourescence & $1.0-22$ & 0.32 & [55] \\
\hline CdTe composite & Flourescence & $1.3-25$ & 0.5 & [56] \\
\hline 2,6-dimercaptopurine & Colorimetry & $84-336$ & 3.66 & [57] \\
\hline Chalcon carboxylic acid-AgNPs & Colorimetry & $0.227-3.18$ & 0.13 & [58] \\
\hline $\mathrm{SnO}_{2} / \mathrm{Nafion} / \mathrm{Au}$ electrode & $\mathrm{CV}$ & $44.5-400$ & 4.4 & [59] \\
\hline $\begin{array}{l}\text { Chitosan/carbon nanotubes modified } \\
\text { GCE }\end{array}$ & SWASV & $13.3-36$ & 6.5 & {$[60]$} \\
\hline Cd-IIP-MCPE & DPASV & $0.018-1.8$ & 0.03 & {$[61]$} \\
\hline VMSF/ITO & DPV & $1.0-20$ & 0.23 & [62] \\
\hline BiFE SPE & SWASV & $0.99-12.0$ & 0.53 & [63] \\
\hline AuNP/Ru[(NH3)6] $]^{3+} /$ modified GCE & ASV & $2.66-6.12$ & 1.77 & {$[64]$} \\
\hline CoPC/GCE & DPSV & $0-100$ & 0.34 & {$[65]$} \\
\hline Back-to-back 6B pencil electrode & ASV & $0.87-3.33$ & 2.2 & {$[66]$} \\
\hline PANI-MWCNT-APTES-GCE & LSV & $0.05-50$ & 0.0155 & This Work \\
\hline
\end{tabular}




\section{Conclusions}

The current study focused on detecting $\mathrm{Cd}^{2+}$ ions in water using a newly synthesized composite based on PANI-MWCNT-APTES. The composite was synthesized by the wet chemical method, and its successful synthesis, including XRD, XPS, FESEM, TGA-DTA, FTIR, and CV. The synthesized PANI-MWCNT-APTES was applied for electrochemical sensing of $\mathrm{Cd}$ using linear sweep voltammetry. The sensor gave a linear response to $\mathrm{Cd}^{2+}$ ions in the range of $0.05 \mu \mathrm{M}$ to $50 \mu \mathrm{M}$ with a limit of detection of $15.5 \mathrm{nM}$. It also displayed high sensitivity and stability. In addition, the developed sensor based on a PANI-MWCNTAPTES composite exhibited fast response time, and its current responses were not affected by likely interferents. It was also used satisfactorily for $\mathrm{Cd}^{2+}$ ion determination in real water samples. Therefore, this study provides a cheap and effective method of $\mathrm{Cd}^{2+}$ ion detection in the environment for human health safety and environmental pollution prevention.

Supplementary Materials: The following are available online at https: / / www.mdpi.com/article / 10.3390 / membranes11110853/s1, Figure S1:EIS spectrum for PANI-MWCNT-APTES; Figure S2: EIS spectrum for bare GCE, Table S1 The results of electrical conductivity measurement.

Author Contributions: Conceptualization, R.S.A. and W.A.A.; methodology, R.S.A.; software, W.A.A. and I.K.; validation, R.S.A., W.A.A. and A.K.; formal analysis, R.S.A.; investigation, R.S.A.; resources, A.K. and H.M.M.; data curation, A.E.A.; writing—original draft preparation, R.S.A.; writing-review and editing, A.K. and A.M.A.; visualization, M.J.; supervision, H.M.M.; project administration, A.K.; funding acquisition, H.M.M. All authors have read and agreed to the published version of the manuscript.

Funding: This project was funded by the Deanship of Scientific Research (DSR), King Abdulaziz University, Jeddah Saudi Arabia, under grant number (KEP-Phd-1-130-42).

Institutional Review Board Statement: Not applicable.

Data Availability Statement: Not applicable.

Acknowledgments: This project was funded by the Deanship of Scientific Research (DSR), King Abdulaziz University, Jeddah Saudi Arabia, under grant number (KEP-Phd-1-130-42). The authors, therefore, acknowledge DSR with thanks for the technical and financial support. The authors of this study thank the Center of Excellence for Advanced Materials Research (CEAMR), KAU, for the equipment support.

Conflicts of Interest: There are no known conflicts in this study.

\section{References}

1. Verma, R.; Gupta, B.D. Detection of heavy metal ions in contaminated water by surface plasmon resonance based optical fibre sensor using conducting polymer and chitosan. Food Chem. 2015, 166, 568-575. [CrossRef]

2. Nordberg, G.F. Cadmium and health in the 21st Century - historical remarks and trends for the future. BioMetals 2004, 17, 485-489. [CrossRef]

3. Alizadeh, T.; Ganjali, M.R.; Nourozi, P.; Zare, M.; Hoseini, M. A carbon paste electrode impregnated with Cd ${ }^{2+}$ imprinted polymer as a new and high selective electrochemical sensor for determination of ultra-trace $\mathrm{Cd}^{2+}$ in water samples. J. Electroanal. Chem. 2011, 657, 98-106. [CrossRef]

4. Oyeyiola, A.O.; Adeosun, W.; Fabunmi, I.A. Use of Agricultural Wastes for the Immobilization of Metals in Polluted Soils in Lagos State, Nigeria. J. Health Pollut. 2017, 7, 56-64. [CrossRef] [PubMed]

5. Malik, N.; Biswas, A.K.; Qureshi, T.A.; Borana, K.; Virha, R. Bioaccumulation of heavy metals in fish tissues of a freshwater lake of Bhopal. Environ. Monit. Assess. 2010, 160, 267-276. [CrossRef] [PubMed]

6. CHI, Q.; ZHU, G.; Langdon, A. Bioaccumulation of heavy metals in fishes from Taihu Lake, China. J. Environ. Sci. 2007, 19, 1500-1504. [CrossRef]

7. Zhao, X.; Höll, W.H.; Yun, G. Elimination of cadmium trace contaminations from drinking water. Water Res. 2002, 36, 851-858. [CrossRef]

8. WHO Guidelines for Drinking-Water Quality Recommendations, 3rd ed.; WHO: Geneva, Switzerland, 2006.

9. Bhardiya, S.R.; Asati, A.; Sheshma, H.; Rai, A.; Rai, V.K.; Singh, M. A novel bioconjugated reduced graphene oxide-based nanocomposite for sensitive electrochemical detection of cadmium in water. Sens. Actuators B Chem. 2021, 328, 129019. [CrossRef] 
10. Gawin, M.; Konefał, J.; Trzewik, B.; Walas, S.; Tobiasz, A.; Mrowiec, H.; Witek, E. Preparation of a new Cd(II)-imprinted polymer and its application to determination of cadmium(II) via flow-injection-flame atomic absorption spectrometry. Talanta 2010, 80 , 1305-1310. [CrossRef]

11. Sahmoun, A.E.; Case, L.D.; Jackson, S.A.; Schwartz, G.G. Cadmium and Prostate Cancer: A Critical Epidemiologic Analysis. Cancer Investig. 2005, 23, 256-263. [CrossRef]

12. Golbedaghi, R.; Jafari, S.; Yaftian, M.R.; Azadbakht, R.; Salehzadeh, S.; Jaleh, B. Determination of cadmium(II) ion by atomic absorption spectrometry after cloud point extraction. J. Iran. Chem. Soc. 2012, 9, 251-256. [CrossRef]

13. Lambkin, D.; Alloway, B. The problem of arsenic interference in the analysis of soils for cadmium by inductively coupled plasma-optical emission spectrometry. Sci. Total Environ. 2000, 256, 77-81. [CrossRef]

14. Fang, Y.; Cui, B.; Huang, J.; Wang, L. Ultrasensitive electrochemical sensor for simultaneous determination of cadmium and lead ions based on one-step co-electropolymerization strategy. Sens. Actuators B Chem. 2019, 284, 414-420. [CrossRef]

15. Sacara, A.-M.; Pitzalis, F.; Salis, A.; Turdean, G.L.; Muresan, L.M. Glassy carbon electrodes modified with ordered mesoporous silica for the electrochemical detection of cadmium ions. ACS Omega 2009, 4, 1410-1415. [CrossRef]

16. Kokkinos, C.; Economou, A.; Raptis, I.; Efstathiou, C.E. Lithographically fabricated disposable bismuth-film electrodes for the trace determination of $\mathrm{Pb}(\mathrm{II})$ and $\mathrm{Cd}(\mathrm{II})$ by anodic stripping voltammetry. Electrochim. Acta 2008, 53, 5294-5299. [CrossRef]

17. Hassanpoor, S.; Rouhi, N. Electrochemical sensor for determination of trace amounts of cadmium (II) in environmental water samples based on MnO 2/RGO nanocomposite. Int. J. Environ. Anal. Chem. 2021, 101, 513-532. [CrossRef]

18. Wu, W.; Jia, M.; Wang, Z.; Zhang, W.; Zhang, Q.; Liu, G.; Zhang, Z.; Li, P. Simultaneous voltammetric determination of cadmium(II), lead(II), mercury(II), zinc(II), and copper(II) using a glassy carbon electrode modified with magnetite (Fe3O4) nanoparticles and fluorinated multiwalled carbon nanotubes. Microchim. Acta 2019, 186, 97. [CrossRef] [PubMed]

19. KHAN, A.; KHAN, A. Electrical conductivity and cation exchange kinetic studies on poly-o-toluidine Th(IV) phosphate nanocomposite cation exchange material. Talanta 2007, 73, 850-856. [CrossRef]

20. ul Haque, S.; Inamuddin; Nasar, A.; Rajender, B.; Khan, A.; Asiri, A.M.; Ashraf, G.M. Optimization of Glucose Powered Biofuel Cell Anode Developed by Polyaniline-Silver as Electron Transfer Enhancer and Ferritin as Biocompatible Redox Mediator. Sci. Rep. 2017, 7, 12703. [CrossRef]

21. Khan, A.; Khan, A.A.P.; Rahman, M.M.; Asiri, A.M. High performance polyaniline/vanadyl phosphate (PANI-VOPO4) nano composite sheets prepared by exfoliation/intercalation method for sensing applications. Eur. Polym. J. 2016, 75, 388-398. [CrossRef]

22. Khan, A.; Khan, A.A.P.; Asiri, A.M.; Rahman, M.M.; Alhogbi, B.G. Preparation and properties of novel sol-gel-derived quaternized poly(n-methyl pyrrole)/Sn(II)SiO $3 /$ CNT composites. J. Solid State Electrochem. 2015, 19, 1479-1489. [CrossRef]

23. Baldoví, H.G.; Neaţu, Ş.; Khan, A.; Asiri, A.M.; Kosa, S.A.; Garcia, H. Understanding the Origin of the Photocatalytic $\mathrm{CO}_{2}$ Reduction by $\mathrm{Au}$ - and $\mathrm{Cu}$-Loaded $\mathrm{TiO}_{2}$ : A Microsecond Transient Absorption Spectroscopy Study. J. Phys. Chem. C 2015, 119, 6819-6827. [CrossRef]

24. Khan, A.; Asiri, A.M.; Khan, A.A.P.; Rub, M.A.; Azum, N.; Rahman, M.M.; Al-Youbi, A.O.; Qusti, A.H. Dual nature, self oxidized poly(o-anisidine) functionalized multiwall carbon nanotubes composite: Preparation, thermal and electrical studies. Compos. Part B Eng. 2014, 58, 451-456. [CrossRef]

25. Rahman, M.M.; Khan, S.B.; Marwani, H.M.; Asiri, A.M.; Alamry, K.A.; Rub, M.A.; Khan, A.; Khan, A.A.P.; Azum, N. Facile synthesis of doped $\mathrm{ZnO}-\mathrm{CdO}$ nanoblocks as solid-phase adsorbent and efficient solar photo-catalyst applications. J. Ind. Eng. Chem. 2014, 20, 2278-2286. [CrossRef]

26. Khan, A.; Khan, A.A.P.; Rahman, M.M.; Asiri, A.M.; Inamuddin; Alamry, K.A.; Hameed, S.A. Preparation and characterization of PANI@G/CWO nanocomposite for enhanced 2-nitrophenol sensing. Appl. Surf. Sci. 2018, 433, 696-704. [CrossRef]

27. Narayanasamy, P.; Balasundar, P.; Senthil, S.; Sanjay, M.R.; Siengchin, S.; Khan, A.; Asiri, A.M. Characterization of a novel natural cellulosic fiber from Calotropis gigantea fruit bunch for ecofriendly polymer composites. Int. J. Biol. Macromol. 2020, 150, 793-801. [CrossRef]

28. Khan, A.; Asiri, A.M.; Kosa, S.A.; Garcia, H.; Grirrane, A. Catalytic stereoselective addition to alkynes. Borylation or silylation promoted by magnesia-supported iron oxide and cis-diboronation or silaboration by supported platinum nanoparticles. J. Catal. 2015, 329, 401-412. [CrossRef]

29. Ramaprasad, A.T.; Rao, V.; Sanjeev, G.; Ramanani, S.P.; Sabharwal, S. Grafting of polyaniline onto the radiation crosslinked chitosan. Synth. Met. 2009, 159, 1983-1990. [CrossRef]

30. Saini, P. Fundamentals of Conjugated Polymer Blends, Copolymers and Composites: Synthesis, Properties, and Applications; WileyScrivener: Hoboken, NJ, USA, 2015.

31. Rohani, T.; Taher, M.A. Novel functionalized multiwalled carbon nanotube-glassy carbon electrode for simultaneous determination of ascorbic acid and uric acid. Arab. J. Chem. 2018, 11, 214-220. [CrossRef]

32. Dhibar, S.; Bhattacharya, P.; Hatui, G.; Das, C.K. Transition metal doped poly(aniline-co-pyrrole)/multi-walled carbon nanotubes nanocomposite for high performance supercapacitor electrode materials. J. Alloys Compd. 2015, 625, 64-75. [CrossRef]

33. He, W.; Wang, F.; Jia, D.; Li, Y.; Liang, L.; Zhang, J.; Hao, Q.; Liu, C.; Liu, H.; Zhao, J. Al-doped nickel sulfide nanosheet arrays as highly efficient bifunctional electrocatalysts for overall water splitting. Nanoscale 2020, 12, 24244-24250. [CrossRef] 
34. Zhang, D.; Wu, Z.; Li, P.; Zong, X.; Dong, G.; Zhang, Y. Facile fabrication of polyaniline/multi-walled carbon nanotubes/molybdenum disulfide ternary nanocomposite and its high-performance ammonia-sensing at room temperature. Sens. Actuators B Chem. 2018, 258, 895-905. [CrossRef]

35. Ahmed, D.S.; Haider, A.J.; Mohammad, M.R. Comparesion of Functionalization of Multi-Walled Carbon Nanotubes Treated by Oil Olive and Nitric Acid and their Characterization. Energy Procedia 2013, 36, 1111-1118. [CrossRef]

36. Zhou, Y.; Liu, J.; Huang, R.; Zhang, M.; Xiao, M.; Meng, Y.; Sun, L. Covalently immobilized ionic liquids on single layer nanosheets for heterogeneous catalysis applications. Dalt. Trans. 2017, 46, 13126-13134. [CrossRef] [PubMed]

37. Peng, B.; Takai, C.; Razavi-khosroshahi, H.; Fuji, M. Effect of silane modification on CNTs/silica composites fabricated by a non-firing process to enhance interfacial property and dispersibility. Adv. Powder Technol. 2018, 29, 2091-2096. [CrossRef]

38. Yang, X.; He, Y.; Zeng, G.; Chen, X.; Shi, H.; Qing, D.; Li, F.; Chen, Q. Bio-inspired method for preparation of multiwall carbon nanotubes decorated superhydrophilic poly (vinylidene fluoride) membrane for oil/water emulsion separation. Chem. Eng. J. 2007, 321. [CrossRef]

39. Dhand, C.; Arya, S.K.; Datta, M.; Malhotra, B.D. Polyaniline-carbon nanotube composite film for cholesterol biosensor. Anal. Biochem. 2008, 383, 194-199. [CrossRef]

40. Sonawane, S.; Thakur, P.; Paul, R. Study on thermal property enhancement of MWCNT based polypropylene (PP) nanocomposites. Mater. Today Proc. 2020, 27, 550-555. [CrossRef]

41. Zhou, T.Y.; Tsui, G.C.P.; Liang, J.Z.; Zou, S.Y.; Tang, C.Y.; Mišković-Stanković, V. Thermal properties and thermal stability of PP/MWCNT composites. Compos. Part B Eng. 2016, 90, 107-114. [CrossRef]

42. Ma, L.; Luo, P.; He, Y.; Zhang, L.; Fan, Y.; Jiang, Z. Improving the stability of multi-walled carbon nano-tubes in extremely environments: Applications as nano-plugging additives in drilling fluids. J. Nat. Gas Sci. Eng. 2020, 74, 103082. [CrossRef]

43. Kundu, S.; Wang, Y.; Xia, W.; Muhler, M. Thermal Stability and Reducibility of Oxygen-Containing Functional Groups on Multiwalled Carbon Nanotube Surfaces: A Quantitative High-Resolution XPS and TPD/TPR Study. J. Phys. Chem. C 2008, 112, 16869-16878. [CrossRef]

44. Asiri, A.M.; Adeosun, W.A.; Marwani, H.M.; Rahman, M.M. Homopolymerization of 3-aminobenzoic acid for enzyme-free electrocatalytic assay of nitrite ions. New J. Chem. 2020, 44, 2022-2032. [CrossRef]

45. Manual, Scientific Equipment and Services; Thermo Fisher Scientific: Roorkee, India, 2000.

46. Rahman, M.M.; Adeosun, W.A.; Asiri, A.M. Fabrication of selective and sensitive chemical sensor development based on flower-flake $\mathrm{La} 2 \mathrm{ZnO} 4$ nanocomposite for effective non-enzymatic sensing of hydrogen peroxide by electrochemical method. Microchem. J. 2020, 159, 105536. [CrossRef]

47. Apak, R.; Hizal, J.; Ustaer, C. Correlation between the Limiting pH of Metal Ion Solubility and Total Metal Concentration. J. Colloid Interface Sci. 1999, 211, 185-192. [CrossRef]

48. Goseer, D.K. Cyclic Voltametry-Simulation and Analysis of Reaction; VCH: New York, NY, USA, 1993; ISBN 3-527-28226-2.

49. $\mathrm{Wu}, \mathrm{J}$. Electrochemical Behavior and Direct Quantitative Determination of Tanshinone IIA in Micro-emulsion. Int. J. Electrochem. Sci. 2016, 5165-5179. [CrossRef]

50. Bard, A.J.; Faulkner, L. Electrochemical Methods: Fundamentals and Applications; Wiley: New York, NY, USA, 2001.

51. Skoog, D.A.; West, D.M.; Holler, F.J.; Crouch, S.R. Fundamentals of Analytical Chemistry; Cengage Learning: Boston, MA, USA, 2013.

52. Adeosun, W.A.; Asiri, A.M.; Marwani, H.M. Sensitive determination of 2-nitrophenol using electrochemically deposited polymethyl red film for healthcare and environmental safety. Synth. Met. 2020, 261, 116321. [CrossRef]

53. Dehdashtian, S.; Shamsipur, M. Modification of gold surface by electrosynthesized mono aza crown ether substituted catecholterminated alkane dithiol and its application as a new electrochemical sensor for trace detection of cadmium ions. Colloids Surfaces B Biointerfaces 2018, 171, 494-500. [CrossRef] [PubMed]

54. Wu, Q.; Zhou, M.; Shi, J.; Li, Q.; Yang, M.; Zhang, Z. Synthesis of Water-Soluble Ag 2 S Quantum Dots with Fluorescence in the Second Near-Infrared Window for Turn-On Detection of Zn(II) and Cd(II). Anal. Chem. 2017, 89, 6616-6623. [CrossRef]

55. Brahim, N.B.; Mohamed, N.B.H.; Echabaane, M.; Haouari, M.; Chaâbane, R.B.; Negrerie, M.; Ouada, H. Ben Thioglycerolfunctionalized CdSe quantum dots detecting cadmium ions. Sens. Actuators B Chem. 2015, 220, 1346-1353. [CrossRef]

56. Xu, H.; Miao, R.; Fang, Z.; Zhong, X. Quantum dot-based "turn-on" fluorescent probe for detection of zinc and cadmium ions in aqueous media. Anal. Chim. Acta 2011, 687, 82-88. [CrossRef]

57. Hu, M.H.; Huang, W.H.; Suo, L.L.; Zhou, L.H.; Ma, L.F.; Zhu, H.F. Gold nanoparticles functionalized with 2,6-dimercaptopurine for sensitive and selective colorimetric determination of cadmium(II) in food, biological and environmental samples. Anal. Methods 2017, 9, 5598-5603. [CrossRef]

58. Dong, Y.; Ding, L.; Jin, X.; Zhu, N. Silver nanoparticles capped with chalcon carboxylic acid as a probe for colorimetric determination of cadmium(II). Microchim. Acta 2017, 184, 3357-3362. [CrossRef]

59. Bhanjana, G.; Dilbaghi, N.; Kumar, R.; Umar, A.; Kumar, S. Sno2 quantum dots as novel platform for electrochemical sensing of cadmium. Electrochim. Acta 2015, 169, 97-102. [CrossRef]

60. Wu, K.-H.; Lo, H.-M.; Wang, J.-C.; Yu, S.-Y.; Yan, B.-D. Electrochemical detection of heavy metal pollutant using crosslinked chitosan/carbon nanotubes thin film electrodes. Mater. Express 2017, 7, 15-24. [CrossRef]

61. Ashkenani, H.; Taher, M.A. Determination of cadmium(II) using carbon paste electrode modified with a Cd-ion imprinted polymer. Microchim. Acta 2012, 178, 53-60. [CrossRef] 
62. Cheng, B.; Zhou, L.; Lu, L.; Liu, J.; Dong, X.; Xi, F.; Chen, P. Simultaneous label-free and pretreatment-free detection of heavy metal ions in complex samples using electrodes decorated with vertically ordered silica nanochannels. Sens. Actuators $B$ Chem. 2018, 259, 364-371. [CrossRef]

63. Figueiredo-Filho, L.C.S.; Janegitz, B.C.; Fatibelilo-Filho, O.; Marcolino-Junior, L.H.; Banks, C.E. Inexpensive and disposable copper mini-sensor modified with bismuth for lead and cadmium determination using square-wave anodic stripping voltammetry. Anal. Methods 2013, 5, 202-207. [CrossRef]

64. Palisoc, S.; Causing, A.M.; Natividad, M. Gold nanoparticle/hexaammineruthenium/Nafion®modified glassy carbon electrodes for trace heavy metal detection in commercial hair dyes. Anal. Methods 2017, 9, 4240-4246. [CrossRef]

65. Fomo, G.; Nwaji, N.; Nyokong, T. Low symmetric metallophthalocyanine modified electrode via click chemistry for simultaneous detection of heavy metals. J. Electroanal. Chem. 2018, 813, 58-66. [CrossRef]

66. Foster, C.W.; Brownson, D.A.C.; Ruas de Souza, A.P.; Bernalte, E.; Iniesta, J.; Bertotti, M.; Banks, C.E. Pencil it in: Pencil drawn electrochemical sensing platforms. Analyst 2016, 141, 4055-4064. [CrossRef] 